\title{
ACERCA DE FRONTINO Y ¿SUS? STRATEGEMATA
}

LOIS C. PÉREZ CASTRO

Instituto de Filología, CSIC

The three books of the Strategemata are believed to be the work of Iulius Frontinus, a well known and most respected military commander, politician and lawyer, who held high-ranking public offices. But there are some facts that make debatable attribution to him of these books.

Sabido es de antiguo que el libro de $\sigma \tau \rho \alpha \tau \eta \gamma$ ıá incluído en la colección de memorabilia relacionados con la res militaris que anda a nombre de Frontino no es del mismo autor que los tres de $\sigma \tau \rho \alpha \tau \eta \gamma \eta \dot{\mu} \mu \tau \alpha$, tenidos por genuinamente frontinianos ${ }^{1}$. A mi entender, la atribución es dudosa y discutible, puesto que en esos tres libros encuentro algunos hechos que a mí no me parecen propios del Julio Frontino del que tenemos noticia.

De este personaje sabemos por Tácito, en efecto, que fue jefe militar muy competente ${ }^{2}$; por Plinio el joven, que fue uno de los jurisconsultos más respetados de su tiempo ${ }^{3}$, y modelo de aquella grauitas arquetípicamente romana, esencial seriedad o, mejor dicho, severidad y austeridad que puso de manifiesto prohibiendo tajante y expresamente que se le construyera

1 Me remito a la exposición, completa y resumida, que bajo el título «The Life and Works of Sextus Julius Frontinus» hizo en su edición (Londres, 1925) Mary B. McElwain.

2 Tac., Agr. 17.2: ... subiit sustinuitque molem Iulius Frontinus, uir magnus, quantum licebat, ualidamque et pugnacem Silurum gentem armis subegit, super uirtutem hostium locorum quoque difficultates eluctatus.

3 Plin., Epist. V 1.5: ... adhibui in consilium duos quos tunc ciuitas nostra spectatissimos habuit, Corellium et Frontinum.

EMERITA (EM) LXVII 1, 1999 - pp. 39-47 
monumento funerario, por cuanto juzgaba que el gasto, por modesto que fuera, había de ser superfluo, ya que estaba convencido de que sólo los merecimientos en vida garantizaban fama y memoria duradera ${ }^{4}$; por sus tratados sobre el sistema de abastecimiento de aguas de Roma y sobre aspectos jurídicos y técnicos de la agrimensura, tenemos constancia de que era autor, ya que no ameno, sí muy riguroso y "científico"; por Eliano el táctico, hay certeza de que era estudioso de la res militaris, además de muy entendido en ella, y de que se interesaba especialmente por lo tocante a la $\delta 1 \alpha \tau \alpha^{\prime} \xi 1 \varsigma^{5}$. Y, para terminar, el propio Frontino nos ha dejado, en el prólogo de su tratado de aquis, un esbozo de autorretrato intelectual y ético:

\begin{abstract}
cum ... sit ... nunc mihi ab Nerua Augusto ... aquarum iniunctum officium cum ad usum tum ad salubritatem atque etiam ad securitatem urbis pertinens, administratum per principes semper ciuitatis nostrae uiros, primum ac potissimum existimo, sicut in ceteris negotiis institueram, nosse quod suscepi. | neque enim ullum omnis actus certius fundamentum crediderim, aut aliter quae facienda quaeque uitanda sint posse decerni, aliutue tam indecorum tolerabili uiro, quam delegatum officium ex adiutorum agere praeceptis, quod fieri necesse est, quotiens imperitia praepositi ad illorum decurrit usum, quorum etsi necessariae partes sunt ad ministerium, tamen ut manus quaedam et instrumentum agentis esse debent. | quapropter ea quae ad uniuersam rem pertinentia contrahere potui, more iam per multa mihi officia seruato, in ordinem et ultra hoc in corpus deducta in hunc commentarium contuli, quem pro formula administrationis respicere possem. | in aliis autem libris, quos post experimenta et usum conposui, succedentium res acta est; huius commentarii pertinebit fortassis et ad successorem utilitas, sed cum inter initia administrationis meae scriptus sit, in primis ad meam institutionem regulamque proficiet. (Frontin., Aq. 1.1-2.3).
\end{abstract}

Salta a la vista que éste era uno de aquellos romanos de pura cepa que apreciaban sobre todo, y casi exclusivamente, la ė $\mu \pi \varepsilon ı \rho^{\prime} \alpha$, y entendían que la falta de ésta, la imperitia, era causa de deshonra por cuanto forzaba a los ministros a actuar siguiendo el criterio de sus ministriles. En un hombre así, nada podía haber de la fatuidad característica de los sabios de gabinete; y de

$4 \quad$ Plin., Epist. IX 19.6: ... uetuit exstrui monumentum, sed quibus uerbis? 'impensa monumenti superuacua est; memoria nostri durabit, si uita meruimus'.

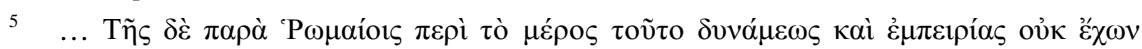

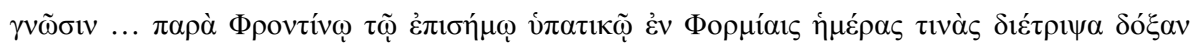

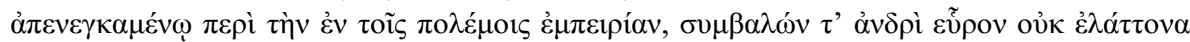

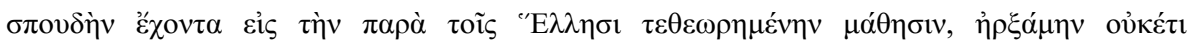

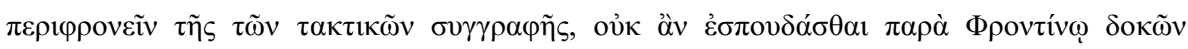

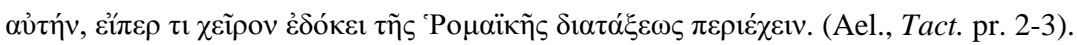


un hombre así no podrían esperarse, y menos demandarse, remedios para la incompetencia meramente paliativos, calidad que tendrían los Strategemata si se da crédito a su prólogo:

cum ad instruendam rei militaris scientiam unus ex numero studiosorum eius accesserim eique destinato, quantum cura nostra ualuit, satisfecisse uisus sim, deberi adhuc institutae arbitror operae, ut sollertia ducum facta, quae a Graecis una $\sigma \tau \rho \alpha \tau \eta \gamma \eta \mu \alpha ́ \tau \omega \nu$ appellatione comprehensa sunt, expeditis amplectar commentariis. ita enim consilii quoque et providentiae exemplis succincti duces erunt, unde illis excogitandi generandique similia facultas nutriatur; praeterea continget, ne de euentu trepidet inuentionis suae, qui probatis eam experimentis comparabit. illud neque ignoro neque infitior, et rerum gestarum scriptores indagine operis sui hanc quoque partem esse complexos et ab auctoribus exemplorum, quidquid insigne aliquo modo fuit, traditum. sed, ut opinor, occupatis uelocitate consuli debet. longum est enim singula et sparsa per immensum corpus historiarum persequi, et hi, qui notabilia excerpserunt, ipso uelut aceruo rerum confuderunt legentem. nostra sedulitas impendet operam, ut, quemadmodum res poscet, ipsum quod exigitur quasi ad interrogatum exhibeat. circumspectis enim generibus, praeparaui opportuna exemplorum ueluti consilia. ... (Strat. I praef.).

Según eso, la colección de memorabilia relacionados con la guerra que anda a nombre de Frontino sería un repertorio - o, mejor dicho, jun prontuario! - de praecepta estratégicos, o consilia, puestos a disposición de los generales en apuros. La idea es a todas luces ridícula, e impropia absolutamente del Julio Frontino histórico. Pero, ciertamente, no puede descartarse de antemano la posibilidad de que ese prólogo sea espúreo, obra de un estratega de café que hubiera dado en la flor de refundir, poniendo el conjunto al amparo de un nombre prestigioso, el libro de $\sigma \tau \rho \alpha \tau \eta \gamma$ iká de un autor con los de $\sigma \tau \rho \alpha \tau \eta \gamma \eta \dot{\eta} \mu \tau \alpha$ de otro, que, en principio, podría ser efectivamente Frontino, puesto que es casi seguro que sus disertaciones so-

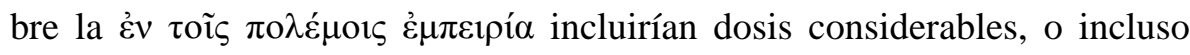
masivas, de ejemplos, o sea de $\sigma \tau \rho \alpha \tau \eta \eta \dot{\mu} \mu \alpha \tau \alpha$, dado que estos son, considerados de cierta manera no del todo ilegítima, "experiencias", o $\varepsilon \mu$ $\pi \varepsilon$ píal, cuya clasificación bien podría imputarse al acreditado rigor científico de Frontino.

Pero en esos tres libros se encuentran algunos hechos verdaderamente significativos, aunque no desde el punto de vista estadístico, que permiten acusar al autor de los Strategemata de falta de rigor, por cuanto es evidente que más de una vez prestó al "colorido" del relato y del vocabulario de re militari 
más atención que a la exactitud y a la tecnicidad. Pues es patente, en efecto, que "mejoró" escandalosamente por lo menos una de las noticias históricas que transmite, y es también evidente que "enriqueció" el léxico militar latino con algunas aportaciones o invenciones, gratuitas y más bien necias, que no podrían de ninguna manera pasar por frutos del ingenio de un hombre tan entendido en la res militaris y tan serio en todo como Julio Frontino.

De la eventual falta de rigor histórico del autor de los Strategemata da fe su adaptación, digna de un guionista moderno, de la siguiente noticia, cuya fuente primera, de autoridad indiscutible, tuvo que conocer y manejar:

sed quantum opere processerant et castra protulerant, tanto aberant ab aqua longius, et praesenti malo aliis malis remedia dabantur. | prima nocte aquandi causa nemo egreditur ex castris; proximo die ... uniuersas ad aquam copias educunt, pabulatum emittitur nemo. | his eos suppliciis male haberi Caesar et necessariam subire deditionem quam proelio decertare malebat. conatur tamen eos uallo fossaque circummunire, ut quam maxime repentinas eorum eruptiones demoretur, quo necessario descensuros existimabat. | illi et inopia pabuli adducti et quo essent ad iter expeditiores, omnia sarcinaria iumenta interfici iubent. (Caes., Ciu. I 81.4-7).

En el segundo libro de los Strategemata, bajo el epígrafe de tempore ad pugnam eligendo, la circummunitio que intentó tender - conatur - César como obstáculo retardador - demoretur - se presenta como obra de cerco concluída, y ejecutada con el expreso propósito de hacer padecer sed extrema a los contrarios, cuyo deseo de huir ligeros de equipaje aparece transmutado en furiosa decisión de combatir a la desesperada:

C. Caesar bello ciuili, cum exercitum Afranii et Petrei circumuallatum siti angeret isque ob hoc exasperatus interfectis omnibus impedimentis ad pugnam descendisset, continuit suos, arbitratus alienum dimicationi tempus, quod aduersarios ira et desperatio incenderet. (Strat. II 1.11).

Nótese que el sacrificio de las acémilas - único punto en el que se atiene a su fuente el autor de los Strategemata (no he de llamarle Frontino) -, hecho justificado y conforme a la ratio rei militaris en el original, habría de entenderse en esta "versión libre" como muestra de locura delirante, y tómese también buena nota de lo "técnico" que resulta usar impedimenta en lugar de sarcinaria iumenta, locución demasiado, y evidentemente, "común”.

En cuanto al léxico relacionado con la res militaris de los Strategemata, hay que señalar especialmente, como rasgos peculiares: 
$1^{\circ}$ El uso del vocablo común uires con el significado de 'tropas', acepción que regularmente reviste el también vocablo común copiae:

parum fidenti uiribus quae sub ipso erant ... cum deinde in Umbria occultatis itineribus collegae se iunxisset, uetuit castra ampliari, ne quod signum adventus sui Poeno daret, detractaturo pugnam, si consulum iunctas uires intellexisset. igitur inscium duplicatis aggressus copiis superavit ... (Strat. I 1.9).

... nuntiauerunt suis pugnam imminere: at illi, ne sub exspectatione proelii diducerent uiris, omiserunt occurrere eis ... (Strat. I 8.5).

... admoto etiam subsidio suis in prima acie, uniuersis uiribus oppressum fudit hostem. (Strat. II 1.8).

... ita frustrato robore exercitus, ipse optuma parte uirium suarum dextro cornu totam circumiit aciem hostium et auertit. (Strat. II 3.3).

... diductis in latera uiribus ... ex utraque parte circumuenerunt eum .... (Strat. II 3.8).

... iussit, qua praecipue conspicui forent hostibus, redire in castra et accedentium nouarum uirium speciem praebere: atque ita simulatis auxiliis tutus est, donec instrueretur exspectatis. (Strat. II 12.3).

... qua re adducti Syracusani uniuersis uiribus Catinam petituri processerunt, relicta ipsorum urbe, quam a tergo adortus Alcibiades ac desolatam ... afflixit. (Strat. III 6.6).

$2^{\circ}$ El empleo de frons, también éste vocablo común, para designar el centro de la línea de batalla, usurpando el lugar del tecnicismo media acies:

... ut animaduertit frontem hostium stipatam electis de toto exercitu uiris, latera autem infirmiora, fortissimis suorum in dextro cornu collocatis, sinistrum latus hostium inuasit ... (Strat. II 3.2).

... latius quam hostes acie instructa in fronte peditem, equitem leuemque armaturam in cornibus collocauit: atque ita ex industria lentius procedente media acie copias hostium cinxit ceciditque. (Strat. II 3.6).

... diductis in latera uiribus uacua fronte ex utraque parte circumuenerunt eum ... (Strat. II 3.8).

... robur legionis triplici acie in fronte ... opposuit ... equitatum ... in cornua diuisit et dextro Romanis equitibus Laelium, sinistro Numidis Masinissam praeposuit: quae tam prudens ordinatio non dubie causa uictoriae fuit. (Strat. II 3.16).

$3^{\text {o }}$ La acepción, sin lugar a dudas impropia, de agmen como 'grupo, batallón', haciendo referencia a un cuerpo de tropas estacionario:

... ubi uidit ex suspecto iugo magnam uim auium simul euolasse neque omnino residere, arbitratus latere illic agmen hostium ... (Strat. I 2.8).

... qui ad fidem faciendam gladios et scuta nostris tradiderunt et in ultimum agmen recepti, ubi primum concurri coepit, strictis minoribus quos occultauerant gladiis, scutis iacentium assumptis, Romanorum aciem ceciderunt. (Strat. II 5.27). 
$4^{\text {o }}$ La resemantización del verbo decerno - 'decidir, decretar, resolver, sentenciar' y, tratándose de guerras o campañas, 'decidir el resultado de un conflicto' - que aparece tomado como si fuera sinónimo de pugno, proelior, etc., y conmutable con éstos:

... cum ... castra super ripam posuisset multoque maiorem hostium manum esse intellegeret et ideo suos arcere a cupiditate decernendi uellet, dixit responso deum se ex collibus pugnare iussum ... (Strat. I 10.3).

... fugientem Mithridatem cupiens ad proelium compellere, elegit tempus dimicationi nocturnum, ut abeunti se opponeret: atque ita praeparatus subitam hostibus necessitatem decernendi iniecit. ... (Strat. II 1.12).

... cum Hasdrubal bello Punico secundo decernendi necessitatem euitans in colle confragoso post uineas aciem direxisset ... (Strat. II 3.8).

Extremando la tolerancia, podría llegarse a pasar por alto la substitución del habitual copiae por uires, atendiendo a la relativa ambigüedad de copiae, que, como es bien sabido, se usa alternativa e indistintamente para designar las tropas y los recursos de toda clase necesarios para la guerra. Pero, por mucho que se quiera buscar, no se encontrará ni una sola razón de cierto peso para justificar el empleo de frons como si fuera término técnico de la milicia, puesto que no se refiere al "frente", sino sólo a una parte de éste para la que la terminología militar latina disponía ya de denominación específica. Como única explicación, que no justificación, posible puede alegarse el hecho de que frons podía entenderse asociado naturalmente a cornua, que es como se llamaban técnicamente las divisiones de flanqueo. Pero esta explicación no confiere ni un ápice de tecnicidad a frons, cuya utilización como si fuera término militar habrá de juzgarse licencia tolerable sólo en una obra sin ninguna pretensión técnica.

Por lo que se refiere al uso impropio y abusivo de agmen y de decerno, debe notarse especialmente que en toda la literatura anterior agmen significa invariablemente 'tropel, masa o grupo en movimiento' - es de rigor dada su manifiesta relación etimológica con ago, verbo de "acción" y "movimiento" por excelencia -, y que decerno conserva intacto su significado propio, 'decidir, sentenciar' en los contextos militares. Así lo emplea César una vez, y otra Tácito:

Caesar postquam Pompeium ad Asparagium esse cognouit, eodem cum exercitu profectus ... tertio die ad Pompeium peruenit iuxtaque eum castra posuit et postridie eductis omnibus copiis acie instructa decernendi potestatem Pompeio fecit. | ubi illum 
suis locis se tenere animum aduertit, reducto in castra exercitu aliud sibi consilium capiendum existimauit. | itaque postero die omnibus copiis ... Dyrrachium profectus est sperans Pompeium aut Dyrrachium compelli aut ab eo intercludi posse, quod omnem commeatum totiusque belli adparatum eo contulisset: ut accidit. (Caes., Ciu. III 41.1-3).

... his cum copiis finis hostium ingressus composito agmine, cuncta explorans paratusque decernere, haud procul Hierosolymis castra facit. (Tac., Hist. V 1.2).

En esos dos casos, verdaderamente excepcionales ${ }^{6}$, el uso de decerno parece propio y "técnico", ya que ahí significa, evidentemente, 'decidir (en un solo encuentro) el resultado de la guerra'. A las pretensiones literarias del autor de los Strategemata debe achacarse, creo yo, su mal uso de ese verbo, al que recurriría para subrayar el ardor de los que pedían pelea (I 10.3), o las ansias que padecían los que se veían forzados a combatir (II 1.12, 3.8).

Hay, pues, razones para empezar a poner en tela de juicio la atribución a Frontino de los tres primeros libros de los Strategemata. Por si ésas fueran poca cosa, hay que reparar también en un hecho de suma importancia: en el

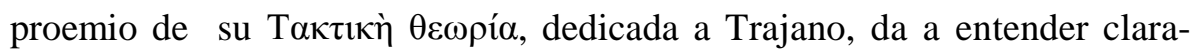
mente Eliano ${ }^{7}$ que en el reinado de Nerva, cuando él visitó a Frontino, éste todavía no se había puesto a redactar su obra de re militari, que, si Vegecio no se equivoca ni miente ${ }^{8}$, mereció la aprobación de Trajano, en cuyo reinado hemos de suponer que se publicó. Si así es, se hace difícil entender cómo y por qué desafiaría un personaje público la damnatio memoriae dictada contra el último de los Flavios mencionándolo, y además con elogio:

imperator Caesar Domitianus Augustus Germanicus, cum Germanos ... uellet opprimere nec ignoraret maiore bellum molitione inituros, si aduentum tanti ducis

6 En otros autores, y señaladamente en Livio, se encuentra este verbo formando, en compañía de un instrumental - acie, ferro, armis -, una iunctura que, muy libremente, podría traducirse por 'luchar', en especial cuando se trata de un duelo a muerte o combate singular. Pero no hay nada que haga pensar que la tal iunctura llegara a adquirir la calidad de modismo consolidado en el uso. Cf. J. Costas, Aspectos del vocabulario de Q. Curtius Rufus, Salamanca, 1980, pp. 109 y siguientes. Curcio toma cuatro veces - III 2.1, 8.18-19, 11.1, IV 12.5 - decerno como sinónimo de pugno, lo que en su caso puede muy bien imputarse a un absoluto desconocimiento de la milicia y su lenguaje. Pero esa no podría de ninguna manera ser la causa de que incurriera en esa flagrante impropiedad el Frontino que precedió a Agrícola en el gobierno militar de lo que es hoy la Gran Bretaña.

7 Cf. supra, n. 5.

$8 \quad$ V. el pasaje citado en la página siguiente. 
praesensissent, profectioni suae census obtexuit Galliarum: sub quibus inopinato bello affusus contusa immanium ferocia nationum prouinciis consuluit. (Strat. I 1.8).

imperator Caesar Domitianus Augustus, cum Germani more suo e saltibus et obscuris latebris subinde impugnarent nostros tutumque regressum in profunda siluarum haberent, limitibus per centum uiginti milia passuum actis non mutauit tantum statum belli, sed et subiecit dicioni suae hostes, quorum refugia nudauerat. (Strat. I 3.10).

auspiciis imperatoris Caesaris Domitiani Augusti Germanici eo bello, quod Iulius Ciuilis in Gallia mouerat, Lingonum opulentissima ciuitas, quae ad Ciuilem desciuerat, cum adueniente exercitu Caesaris populationem timeret, quod contra exspectationem inuiolata nihil ex rebus suis amiserat, ad obsequium redacta septuaginta milia armatorum tradidit mihi. (Strat. IV 3.14).

A la vista de eso, habrá que suponer que fueron compuestos y publicados durante el reinado de Domiciano los tres libros de $\sigma \tau \rho \alpha \tau \eta \gamma \eta \dot{\mu} \mu \alpha \tau$, y que será de esa misma época el de $\sigma \tau \rho \alpha \tau \eta \gamma$ $\alpha \alpha$, que, hallándose exento de impropiedades terminológicas, podría ser obra de un miembro de la clase militar fiel al emperador, que occisum eum grauissime tulit statimque Diuum appellare conatus est, paratus et ulcisci, nisi duces defuissent ${ }^{9}$. No, desde luego, de Frontino, puesto que Eliano no habría podido ni desconocer ni olvidar la existencia de una obra suya sobre la materia.

La que manejó y citó Vegecio, en cuya epitoma no se encuentra ninguna referencia a los Strategemata $^{10}$, trataba de disciplina militari, prestando probablemente atención preferente a los aspectos jurídicos e institucionales de la organización militar, eminentemente funcional, de los romanos:

Cato ille Maior, cum et armis inuictus esset et consul exercitus saepe duxisset, plus se reipublicae credidit profuturum, si disciplinam militarem conferret in litteras. ... idem fecerunt alii complures, sed praecipue Frontinus, diuo Traiano ab eiusmodi comprobatus industria. horum instituta, horum praecepta, in quantum ualeo, strictim fideliterque signabo. nam cum easdem expensas faciat et diligenter et neglegenter exercitus ordinatus, non solum praesentibus, sed etiam futuris saeculis proficit, si prouisione maiestatis tuae, imperator Auguste, et fortissima dispositio reparetur armorum et emendetur dissimulatio praecedentum. | in omnibus auctoribus inuenitur singulos consules, aduersus hostes copiosissimos, non amplius quam binas duxisse legiones ...

9 Suet. VIII 3.23.

10 D. Schenk dedicó cuarenta y cinco de las ochenta y ocho páginas que ocupa su tesis doctoral (Flavius Vegetius Renatus. Die Quellen der Epitoma Rei Militaris, Leipzig, 1930), de la 39 a la 83, a buscar parecidos y coincidencias puntuales entre los Strategemata y el libro III de Vegecio. Trabajo que hay que apreciar en gracia a su tesón, que no a la entidad y consistencia de sus hallazgos. 
tanta in illis erat exercitatio, tanta fiducia, ut cuiuis bello duae legiones crederentur posse sufficere. quapropter ordinationem legionis antiquae secundum normam militaris iuris exponam. (Veg., mil. II 3-4).

Aquí conviene hacer notar que no hay discordancia real entre ese testimonio de Vegecio y el de Eliano, que señalaba la 'P $\omega \mu \alpha \ddot{\kappa} \eta \dot{~} \delta 1 \alpha \tau \alpha \xi_{1 \zeta}$ como especialidad de Frontino, por cuanto $\delta 1 \alpha \tau \alpha \dot{\xi} \xi 1 \zeta$, amén de ser sinónimo de $\pi \alpha \rho \alpha \tau \alpha^{\prime} \xi 1 \varsigma$, se usaba corrientemente, en la documentación oficial de la época, para traducir constitutio, 'reglamentación, ordenanza'. Consiguientemente, podemos dar por seguro que Frontino se ocupó de las instituciones militares romanas, que en buena medida eran puramente técnicas por cuanto la articulación de las legiones en cohortes y la subdivisión de éstas en centurias reflejaba con fidelidad el esquema táctico - genialmente sencillo y por eso mismo inmejorable e inmutable - de los romanos, que se mantuvo sin cambios realmente substanciales a lo largo de toda la historia militar de Roma, y llegó, lo mismo que su admirablemente sencillo y eficaz sistema de castrametación, a institucionalizarse de facto: no había, en rigor, una doctrina técnica mínimamente formalizada y con una base teórica, sino una prác-

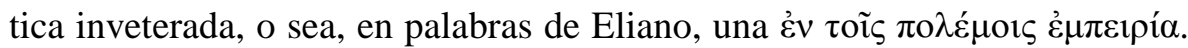
Por decirlo de otra manera, el propósito de Frontino, y antes el de Catón, habría sido pura y simplemente poner por escrito las "ordenanzas" consuetudinarias vigentes en los ejércitos, y no teorizar como los griegos acerca de los principios de la guerra y del arte del generalato, asuntos por los que no manifestaban ningún interés los romanos, convencidos - o conscientes - de que la verdadera scientia rei militaris procedía de la experiencia, y no del estudio $^{11}$. De ahí que Eliano se sorprendiera agradablemente de haber halla-

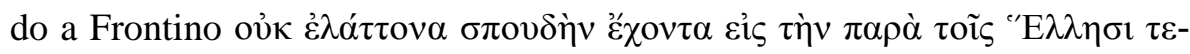

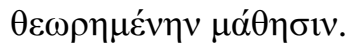

Fuera de una rúbrica en un códice, nada hay, pues, que avale o autorice la atribución a Frontino de los tres libros de $\sigma \tau \rho \alpha \tau \gamma \gamma \tilde{\mu} \mu \alpha \tau \alpha$ o del libro de

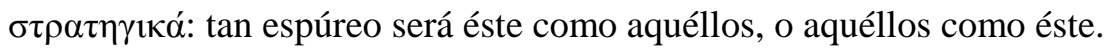

11 Cf. las opiniones manifestadas a este respecto por Cicerón (Font. 43 y, especialmente, Manil. 28) y, según Salustio (Iug. 85.12) por el gran Mario, autor, o principal fautor, del proceso de reformas que llevaron a la perfección la maquinaria militar romana. 